\title{
Responsabilidad y organismos públicos. Receptividad al mundo político, a los usuarios y a las fuerzas del mercado
}

\section{Alain Turc **}

La obligación que tiene la Administración pública de rendir cuentas a los ciudadanos se inscribe en los textos fundadores de la República francesa. La Declaración de los Derechos del Hombre y del Ciudadano de 26 de agosto de 1789 así lo establece:

"La sociedad tiene derecho a pedir cuentas de su administración a todo agente público ... Todos los ciudadanos tienen derecho a comprobar, por ellos mismos o a través de sus representantes, la necesidad de la contribución pública ... y a conocer el empleo que se hace de ellan.

Esta declaración se inscribe en el preámbulo de la Constitución francesa actual.

La aplicación de estos principios había debido ser facilitada, en principio, por la organización de la Administración francesa muy formalizada, caracterizada, desde hace mucho tiempo, por:

- unos ministros responsables de la organización de sus servicios, que deben dar cuenta al Parlamento de la utilización de los créditos que se les asignan;

- un dispositivo legislativo y reglamentario muy detallado;

- un control de las cuentas públicas ejercido por el Tribunal de Cuentas (Cour des Comptes);

- la posibilidad del ciudadano de hacer examinar sus discrepancias con la Administración por vía jerárquica (dirigiéndose al ministro correspondiente) o contenciosa (llevando el asunto ante una jurisdicción especializada, el tribunal administrativo).

La experiencia histórica demuestra que esto no es suficiente para asegurar plenamente la transparencia de la Administración pública. Las razones se deben a los problemas estructurales en los que se encuentra toda organización de grandes dimensiones, tanto en Francia como en otros países ${ }^{1}$ :

- el aumento de la complejidad con el tiempo, debido a la multiplicación de las intervenciones y la acumulación de reglas de gestión;

- la frecuente dificultad para reagrupar las distintas acciones en programas o proyectos coherentes, con un responsable determinado y con resultados fácilmente medibles;

- la transparencia insuficiente tanto para los ciudadanos como para los funcionarios (lo que se traduce, a menudo, en la imposibilidad práctica de determinar el conjunto de servicios implicados en la ejecución de una medida, o de apreciar plenamente cuáles pueden ser todas sus repercusiones);

- la atención prestada principalmente a la gestión normal y repetitiva, en detrimento de una visión plurianual y estratégica;

- la dificultad para realizar el nuevo despliegue de créditos y medios necesarios o para tener en cuenta la evolución de las necesidades y las prioridades.

Estos problemas no han impedido a la Administración francesa llevar a cabo un programa muy importante de modemización a lo largo de los últimos treinta años ${ }^{2}$. Se puede pensar, no obstante, que han complicado su realización, aun cuando la modemización efectuada haya visto acompañada la resolución estructural de algunos de estos problemas ${ }^{3}$. 
Por ello, la reforma del Estado llevada a cabo bajo la autoridad del Primer Ministro se articula en torno a tres grandes preocupaciones:

- un Estado menos complicado y al servicio del ciudadano;

- un Estado más eficaz;

- un Estado más transparente.

La Administración debe, en efecto, responder mejor a las demandas de transparencia, de simplificación y de eficacia que le pide la sociedad.

\section{Un Estado más simple y al servicio del ciudadano}

Las acciones impulsadas por el Comisariado para la reforma del Estado, de acuerdo con las orientaciones definidas por el Primer Ministro, han estado dirigidas hacia:

\section{La reducción y agilización de los trámites administrativos}

El inventario sistemático de los trámites para las autorizaciones administrativas previas impuestas a los particulares o a las empresas ha permitido identificar cerca de 4.000 actos de ese tipo. Se ha tomado la decisión de suprimir algunos de ellos, o reemplazarlos, bien por una simple declaración, o por una autorización tácita en caso de silencio administrativo.

Se ha puesto en marcha un primer grupo de 300 medidas simplificadoras por Decreto de 21 de mayo de 1997. Un segundo grupo de 450 nuevas medidas simplificadoras se aplicará en los próximos meses.

\section{La modernización y la simplificación de los procedimientos administrativos}

La tarea de simplificación de trámites va acompañada de una acción sistemática de simplificación de los procedimientos, que pasa por un mayor empleo de las nuevas tecnologías y el desarrollo de los teleprocesos para la declaración (por ejemplo, las declaraciones sobre soporte papel que se hacian antes por las personas en tránsito ante los servicios de aduanas se efectúan en lo sucesivo por vía electrónica) o la ayuda para la creación de dossiers (los contribuyentes pueden también utilizar un teleproceso que se ha puesto a su disposición por el Ministerio de Hacienda para calcular el importe del impuesto sobre la renta).

\section{Ia desconcentración creciente de las responsabilidades}

La distancia entre el ciudadano y el decisor administrativo, así como la dificultad para encontrar al responsable efectivo, figuran entre las principales causas de las rigideces burocráticas.

La Administración francesa tradicional se caracterizaba por una centralización excesiva de las decisiones a nivel de los ministerios. Esto llevaba a muchos franceses a decir que atodo se decide en París" en un país donde, sin embargo, Napoleón Bonaparte había establecido a principios del siglo XIX una norma de sentido común siempre válida: "No se gobierna bien más que de lejos, no se administra bien sino de cerca».

La descentralización de 1982, que transfirió importantes competencias del Estado a las entidades territoriales ${ }^{4}$ en algunas áreas sensibles, como la acción social, la formación profesional, las obras públicas, ha aproximado, indiscutiblemente, la Administración pública al ciudadano.

La desconcentración, es decir, la transferencia de competencias de los ministerios a los servicios territoriales del Estado en la región o en el departamento, se ha acelerado. El prefecto, único representante del Estado en el departamento, es el responsable de los servicios del Estado allí implantados.

El Decreto de 15 de enero de 1997 prevé que, a partir del $1^{\circ}$ de enero de 1998, el prefecto asumirá el conjunto de decisiones individuales que entran dentro del campo de competencia de las Administraciones civiles del Estado, salvo derogación expresamente definida por decreto de Consejo de Ministros. Esta disposición clarifica el reparto de competencias entre las administraciones centrales y el prefecto, estableciendo como principio de Derecho común la competencia de este último, que es el que más cerca está del ciudadano.

\section{El desarrollo de acciones de calidad dentro de la Administración}

La atención prestada a los derechos de los ciudadanos debe ir acompañada de un empeño en la mejora de la calidad de los servicios que se prestan al público.

El Comisariado para la reforma del Estado ha publicado en 1997, con la Dirección general de administración y función pública, una guía titulada: "Desarrollar la calidad del servicio" que expone los principios y la metodología para la gestión de la calidad en los servicios públicos. Cada una de las grandes redes de servicios que están en contacto con el público debería también poder definir una carta de calidad para ser difundida entre los servicios y a los usuarios. 


\section{Un Derecho más claro y más estable}

Si el adagio dice que ala ignorancia de la ley no excusa de su cumplimiento=, tanto más importante será que la ley y sus textos aplicativos estén claramente expresados, sean accesibles y comprensibles por el ciudadano. Por el contrario, la proliferación de textos, que lleva consigo la falta de claridad y la inestabilidad del Derecho, afecta no sólo a la eficacia del sistema jurídico, sino también al buen funcionamiento de la democracia.

Es importante, pues, procurar la estabilidad del Derecho, verificando que todo nuevo proyecto de texto corresponda a una necesidad real y conlleve una respuesta apropiada temporal y jurídicamente. Desde 1996, los proyectos de ley y los proyectos de decreto en el Consejo de Estado se acompañan, a título experimental, de un estudio de impacto para ilustrar al legislador y al gobiemo sobre los efectos jurídicos, económicos, sociales y financieros del texto propuesto, así como sobre sus consecuencias para el empleo y las simplificaciones administrativas. Este procedimiento acaba de ser confirmado por el Primer Ministro.

\section{Un Estado más eficaz}

Significa una modernización de la gestión, en particular de la gestión financiera, que permita organizar las responsabilidades y el seguimiento de las acciones, sobre la base de objetivos claramente definidos y de indicadores de realización.

\section{Ia modernización de la gestión financiera}

El esfuerzo alcanza en primer lugar a la renovación del procedimiento presupuestario, con vistas a mejorar la dimensión estratégica de las previsiones presupuestarias y a reforzar el papel del Parlamento.

Afecta, luego, a la modernización de la ejecución de los gastos del Estado, con la modernización de las aplicaciones informáticas de gastos puestas en marcha en los años 80 , con el fin de mejorar la información ya proporcionada a los gestores.

Este esfuerzo alcanza, igualmente; a la mejora de la gestión patrimonial del Estado. Está en curso una renovación metodológica para definir un nuevo marco contable del Estado que permita no sólo conocer los gastos, sino también apreciar mejor los elementos de activos y pasivos, con el fin de administrarlos mejor.

\section{El desarrollo de un enfoque objetivos-resultados}

La multiplicación y el incremento en las causas del gasto público, las dificultades de financiación y la necesidad de redu- cir las contribuciones obligatorias exigen una gestión óptima de los gastos públicos, que pasa, por una parte, por un mejor seguimiento de los gastos $y$, por otra, por un enfoque en términos de programas o de proyectos; a fin de evaluar mejor el coste de la eficacia de los gastos comprometidos para una acción determinada.

Esta gestión que se desarrolla dentro de las Administraciones públicas, es indisociable de la mayor responsabilización de los gestores que deben poder responder de los medios que les son asignados, tanto ante el superior jerárquico como ante el Parlamento o los usuarios.

También es una condición necesaria para una relación eficaz entre los ministerios y los servicios desconcentrados del Estado, sobre la base de objetivos y el seguimiento de su realización.

\section{El reparto moderno de responsabilidades}

Los ministerios están llamados en el futuro a ejercer plenamente unas competencias que sólo ellos pueden ejercer: el análisis de las prioridades públicas y de los desafios estratégicos por el Estado, las disposiciones propuestas al Parlamento y la información de este último, la dirección de los servicios locales del Estado. Estos últimos deben, en adelante, asegurar lo esencial de las funciones de administración ordinaria del Estado.

El buen funcionamiento del sistema requiere, además de la clarificación de las competencias, de un dispositivo de información recíproca que permita a cada servicio del Estado conocer en todo momento sus gastos y sus resultados, compararse con servicios de otro departamento y situarse en relación a los resultados nacionales.

\section{Un Estado más transparente}

La transparencia del Estado y de su Administración es necesaria para:

- que se pueda rendir cuentas al Parlamento y a los ciudadanos de la utilización de los medios públicos y de los resultados obtenidos;

- que la administración se gestione mejor: una Administración opaca para los ciudadanos es, generalmente, opaca para ella misma, y ve acrecentarse inevitablemente su ineficiencia;

- impedir el desarrollo de fenómenos burocráticos que se derivan siempre de la disolución de responsabilidades, 
de la ausencia de objetivos, de la insuficiencia de controles o de la falta de atención a los resultados.

Esta transparencia debe incrementarse por las medidas que se indican a continuación:
- la capacidad de rendir cuentas (accountability);

- la responsabilidad de los administradores (responsability);

- la atención responsable a las demandas de los ciudadanos (responsiveness).
Artículo traducido por Elisa ROMERo SEBASTLÁN.

- Este arículo fue publicado en Democratic and Political Accountability. Copyright OCDE, 1997, a quien agradecemos su gentileza en permitimos su reproducción.

- Comisariado para la reforma del Estado, Francia.

' Se puede adelantar la hipótesis de que fenómenos semejantes deben manifestarse igualmente dentro de las grandes organizaciones privadas; aunque sea en formas particulares, teniendo en cuenta que esas organizaciones están supeditadas a las exigencias del mercado.

'Modernización de la gestión interna (clarificación de las competencias. transferencia de competencias del Estado a las entidades territoriales a partir de las leyes de descentralización de 1982, designación del prefecto como representante único del Estado y responsable de los servicios del Estado a nivel local; modemización de los instrumentos y métodos de gestión, especialmente con una informatización impontante de los trámites y procedimientos; incremento de la formación inicial y permanente de los funcionarios; multiplicación de las experiencias de responsabilización de los servicios, etc.) y fortalecimiento de los derechos de los ciudadanos en sus relaciones con la Administración (institución del Mediador de la República en 1973, reforzamiento, luego, de sus poderes, definición de los derechos de acceso a los documentos admi- nistrativos, fijación de plazos para las respuestas de la Administración a los usuarios, etc.).

${ }^{3}$ Por ejemplo, la infomatización de los gastos del Estado se hace por la puesta en funcionamiento de una aplicación informática común a todos los ordenadores de pagos (servicios encargados de la ordenación de la ejecución de los gastos) y a todos los contables (encargados de pagar y de contabilizar), que es utilizada por todos los servicios del Estado. De este modo, cada servicio puede saber en qué momento se encuentra la ejecución de un gasto que le atane (lo que facilita la reducción de retrasos en el pago y la detección de demoras injustificadas); como consecuencia de la centralización nacional, el Ministerio de Hacienda puede conocer cada semana el importe de los gastos efectuados la semana anterior.

4 Las entidades territoriales francesas son la región, el departamento y el municipio. Éstas se gestionan y administran libremente. según el articulo 72 de la Constitución, con una asamblea deliberante elegida (consejo regional; consejo general para el departamento; consejo municipal para el municipio) y un ejecutivo elegido por la asamblea deliberante (el presidente del consejo regional, del consejo general o el alcalde).

'Las decisiones que conciemen a los agentes públicos son objeto de medidas particulares de desconcentración. 